\title{
Based on Fuzzy Bayesian Network of Oil Wharf Handling Risk Assessment
}

\author{
Zhiqiang Hou ${ }^{1,2}$ and Peng Zhao ${ }^{1}$ \\ ${ }^{1}$ School of Traffic and Transportation, Beijing Jiaotong University, Beijing 100044, China
}

${ }^{2}$ Waterborne Transportation Institute, Beijing 100088, China

Correspondence should be addressed to Zhiqiang Hou; zhiqianghou@163.com

Received 14 March 2016; Revised 19 July 2016; Accepted 25 July 2016

Academic Editor: Yuqiang Wu

Copyright (c) 2016 Z. Hou and P. Zhao. This is an open access article distributed under the Creative Commons Attribution License, which permits unrestricted use, distribution, and reproduction in any medium, provided the original work is properly cited.

In order to make the risk assessment method of oil wharf handling more reasonable, basic data calibration method more accurate, and assessment findings more objective, the fuzzy weights of the relative probability of basic events are calibrated by ANP decisionmaking (Analytic Network Process). ANP decision-making is appropriate for reflecting the dependence between the basic events and the feedback relationship. The calibration value is used as the probability value of each basic event. Based on the fault tree model, the relationship between the accidents caused by the Bayesian network is constructed, and the important degree of the basic events is quantitatively evaluated. The case focuses on wharf handling gasoline fire and explosions, using ANP method to calibrate probability, and analyzing and sorting the structural importance, the probability importance, and critical degree of each basic event through forward and backward reasoning. The results showed that the evaluation model can better characterize the effect of the basic events on the top events, which can be targeted to identify security weaknesses in oil wharf handling process. It has some practical significance for finding security risks and improving working conditions and the overall system safety level.

\section{Introduction}

The number of water transports of dangerous goods has increased by $20 \%$ annually over recent decades in China [1], in which oil water transport contributes a lot (or plays an important part). There are great potential risks hiding in oil wharf handling and many potential threats to safety. Once the threats are out of control, accidents such as oil leakage, fire, explosion, and others could happen at any time, causing casualties, property damage, or serious pollution. Therefore, to assess the risk of oil wharf handling process and to identify the key factors that lead to accidents are of great importance to ensure the safe operation at ports.

At present, research papers at home and abroad on risk assessment are easy to find and can be summed up into three categories.

(1) Assessment methods based on the concept of risk management: risk is the function about probability (frequency) and the extent of loss, which assesses the risk value by calculating the probability of accidents (frequency) and the consequences and then compares the value with risk evaluation criteria so as to identify whether it meets the specified security requirements. In [2], an indicator system is built that measures the accidents consequence and probability of major hazard sources in water transport engineering, through which to determine the risk rating by calculating the risk value.

(2) Assessment methods based on traditional theory of security systems engineering, such as Fault Tree Analysis, Event Tree Analysis, Risk Matrix, research of danger and operability, probabilistic risk assessment technology, Dow's chemical fire, and index evaluation of explosion [3]: for example, Cong et al. assessed the risk of maintaining pipelines in petrochemical plants using Fault Tree Analysis [4]. Zhao et al. assessed polypropylene production apparatus qualitatively and quantitatively by applying danger and operability research, combining with Fault Tree Analysis [5].

(3) Assessment methods based on modern mathematical theories: the main methods of evaluation are AHP analysis, Bayesian network, Fuzzy Comprehensive Evaluation, Artificial Neural Network method, Grey Comprehensive Evaluation, and Monte Carlo Simulation Method. For example, 
Zhao et al. analyzed the cause of 94 transportation accidents of hazardous articles in China by Bayesian network [6]. Li et al. proposed the risk assessment method, using the fuzzy analytic hierarchy process and the artificial neural network model [7]. Yang et al. bring in the theory of hesitant fuzzy set, combining with the cloud model theory, to construct a hesitant cloud model to achieve the quantitative assessment of human environment risk. And at last an experiment evaluation on the risk of maritime silk road is carried out [8].

The object system of study is complicated; thus, the above evaluation methods also encountered a number of problems while developing rapidly. For instance, the evaluation methods are unable to present the conditional probability relations among different levels and the interrelations of every node; short of database of all kinds of accidents; processing data by expert scoring methods that is not flexible enough and cannot well reflect the dependence and feedback relations among factors; lack of comprehensive studies across evaluation methods; and so on. Therefore, it is believed that establishing a fault tree for oil wharf handling, mapping it onto Bayesian Network, and, meantime, calibrating the probability of elementary event via Saaty's ANP decision-making method will not only clarify the logic of tree causality clearly and express the conditional probability relations in different layers accurately, but also make the calibration method of probability value more flexible, reasonable, and reliable. Besides, it will be able to quantificationally calculate the structural importance, probable importance, and the critical importance of every elementary event, which can be targeted to identify security weaknesses in oil wharf handling process. It has practical significance for finding security risks, improving working conditions and the overall system safety level.

\section{Analysis of Risk Factors}

Oil wharf handling risk assessment needs an analysis of risk factors in handling process in the first place. Oil wharf handling mainly involves operations such as berthing, mooring, and (electrostatic) jumper connecting of the vessel, connecting pipelines (or marine loading arm), opening the valve, starting the pump, conveying supplies, turning off the pump, cleaning pipelines, disconnecting pipelines (or marine loading arm), closing the valve, disconnecting the jumper, unmooring, and departure. Each of the above-mentioned operations may have certain risks. For example, when conveying supplies, physicochemical properties of different materials require different delivery pressure, temperature, flow rate, and mix heat. Once these conditions are out of control, a physical or chemical explosion or static electricity accumulation could occur. If cleaning pipelines does not follow operation rules, potential safety risks might therefore appear. In addition, pipes on the wharfs are in a wet and corrosive environment. As a result, if they are not comprehensively inspected or have in-service inspection in time, it might lead to leaking or even fire explosion.

Oil in this paper means petroleum products. Dangerous goods are divided into nine categories according to their dangerousness level or their major hazards [9]. Most oil handled at wharf belongs to the 3rd category of flammable liquids, such as gasoline, aviation kerosene, and crude oil. They are all having a flashing point below $61^{\circ} \mathrm{C}$, which identified them as hazardous chemicals of grievous danger [10]. Therefore, inflammability as the inherent attribute of oil is the inner factor that results in accidents. The incentives of accidents can be divided into the natural factors and nonnatural factors. The latter is also known as man-made accidents and will be the research emphasis of this paper while the former is often force majeure. It is currently believed that persons, things, environment, and management are four major risks and harmful factors during production [11]. If operational workers do not loosen or moor the vessel in accordance with operation instruction, they may be injured by cable or fall into water and get drowned. Pipelines may leak due to corrosion or damage for quality reasons. Loopholes or improper implement of security accountability system, security inputs, safety education and inspection, potential safety hazard checking and controlling, allocation of individual protective equipment, and emergency response are all factors that could bring about accidents.

\section{Risk Assessment Methods}

In other articles Bayesian network and ANP calibration methods combined as a new assessment method have not been used. The following will focus on introducing the concept of Bayesian network and its building methods, ANP calibration methods of probability, and the methods of calculating the importance degree of basic events.

3.1. Bayesian Network. Bayesian network, also known as Belief Networks or Probability Networks, provides a natural method to reflect causality and describe the probability relations among variables. Bayesian network also works as a tool to analyze and reason uncertain events by utilizing the probability theory and graph theory. So far, it is one of the most effective theoretical models in the field of expressing and reasoning uncertain knowledge.

Definition 1. Suppose variable $V=\left\{x_{i}\right\}(i=1,2, \ldots, n)$ is a limited set of discrete variable, and $P$ is the joint probability distribution of variable in $V$. Directed Acyclic Graph (DAG) $J=(V, E)$ is a Bayesian network of $P$ if and only if $D$ is the minimal I-map.

Definition 2. A Bayesian network is composed of network structure $J$ and network parameter $\theta$ : namely, $B=(J, \theta)$. $J$ is a DAG, indicating an independent variable condition in $V$. Nodes in the graph are of one-to-one correspondence relation with variables in $V$, and the directed edge in the graph shows the condition dependency of variables. $\theta$ is the conditional probability distribution connected with every variable.

Definition 3. Suppose $A\left(x_{i}\right)$ indicates the descendant node subset of non- $x_{i}$, and $B\left(x_{i}\right)$ indicates the direct parent node; then $P\left(x_{i} / A\left(x_{i}\right), B\left(x_{i}\right)\right)=p\left(x_{i} / B\left(x_{i}\right)\right)$. Given a random set of variables $V=\left\{x_{i}\right\}(i=1,2, \ldots, n)$, the Bayesian network will be a joint conditional probability distribution in $V$, and 


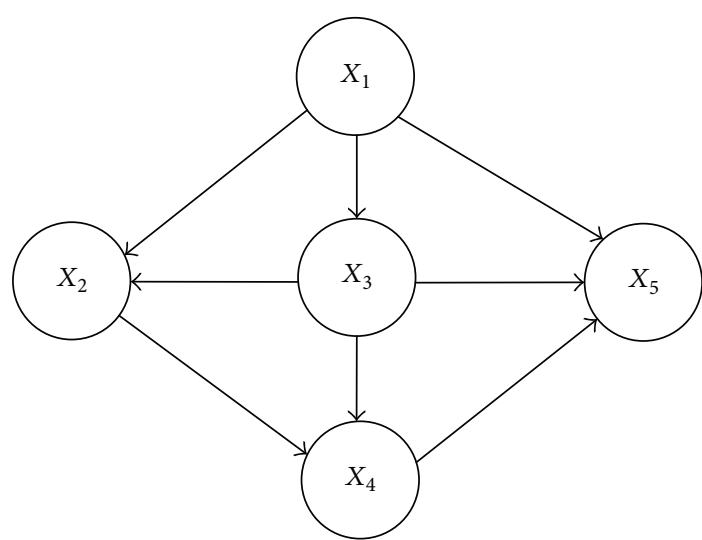

Figure 1: Simple model of Bayesian network.

the joint probability of variable $V=\left\{x_{i}\right\}(i=1,2, \ldots, n)$ is $p\left(x_{i}, \ldots, x_{n}\right)=\prod_{i=1}^{n} p\left(x_{i} / B\left(x_{i}\right)\right)$.

Based on the connections between the node and its father node expressed in the above definitions, a function of joint probability distribution that contains all of the nodes can be deduced.

Figure 1 is a simple Bayesian network. A function of joint probability distribution that contains all of the nodes is

$$
\begin{aligned}
& p\left(x_{1}, x_{2}, x_{3}, x_{4}, x_{5}\right)=p\left(x_{1}\right) p\left(\frac{x_{2}}{x_{1}, x_{3}}\right) p\left(\frac{x_{3}}{x_{1}}\right) \\
& \cdot p\left(\frac{x_{4}}{x_{2}, x_{3}}\right) p\left(\frac{x_{5}}{x_{1}, x_{3}, x_{4}}\right) .
\end{aligned}
$$

The function of joint probability distribution shows the logical relationship among nodes and is the main basis of positive and negative reasoning and quantitative calculation.

3.2. The Building of Bayesian Network for a Fault Tree. A Bayesian network is composed of a DAG $J$ and corresponding conditional probability tables. It is a character of Bayesian network to separately demonstrate events and their uncertainty. In such case, to convert the established system fault tree into a Bayesian network based on certain rules. Referring to the probability distribution of fault reasons (basic events) derived from the analysis of fault data, utilizing the belief propagation and updating from above to below of Bayesian network will lead to a more accurate probability distribution of system fault $[12,13]$. When mapping fault tree model into Bayesian network, the nodes in the network are corresponding one to one with events in the fault tree, which forms a DAG. The conditional probability relations are decided by the logic gate of the fault tree. Figures 2 and 3 are for the mapping relation of And-gate and Or-gate separately.

3.3. ANP Calibration Methods of Probability. Saaty came up with the core concept of analytic hierarchy process (AHP) as early as the beginning of 1980s. Related published literatures on AHP were very huge and exceeded the other decision-making methods [14]. Although AHP is widely used, the criticism on it never stops. The main argument was that the judgment criteria of AHP were not suitable for the complex human thinking and needed to be fuzzification [15]. At the end of 1990s, in [16-18], the fuzzy AHP was invalid that was responded, and Saaty and Tran proposed the theory and method of Analytic Network Process (ANP) based on wide absorption of the research achievements in fields of decisionmaking science. ANP replaced hierarchical relationships with network structural ones and took the dependency of elements into consideration and had effectively made up the disadvantages of AHP. It is more flexible, reasonable, and reliable in dealing with decision-making problems and had thus become one of the most practical and effective decisionmaking methods.

ANP takes the mutual influence of factors or neighboring layers into consideration and makes a comprehensive analysis of the affected factors through hypermatrix to calculate its weight. ANP firstly divides system element into two parts, with the first part being named controlling factors layer. All decision-making guidelines, including the problem target, have been considered to be independent of each other and are subject only to the target element. There can be no decisionmaking guidelines within controlling factors, but there should be at least one target. The weight of each guideline in the controlling layer can be achieved through traditional AHP method. The second part is the network layer. It is composed of all the elements under control of the controlling layer, with mutually affected network structure inside. The calculation steps of ANP [19] are as follows.

(1) Building the Judgment Matrix. Suppose there are elements $B_{1}, B_{2}, \ldots, B_{N}$ in the controlling layer of ANP and $N$ elements set of $C_{1}, C_{2}, \ldots, C_{N}$, where set $C_{i}$ has elements of $e_{i 1}, e_{i 2}, \ldots, e_{i n}(i=1,2, \ldots, N)$. Set $e_{j l}(l=1,2, \ldots, n)$ in $C_{j}$ as the subguideline and compare the impact of $e_{j l}$ through indirect dominance. Use Saaty's scaling method from 1 to 9 to quantitatively build judgment matrix and make normalization processing to achieve eigenvector matrix: $\omega=$ $\left[\omega_{i 1}^{j l}, \ldots, \omega_{i n_{i}}^{j l}\right]^{T}$.

(2) Building the Initial Hypermatrix. After building the judgment matrix, priority vector $\left(\omega_{i 1}^{(j 1)}, \omega_{i 2}^{(j 2)}, \ldots, \omega_{i n_{i}}^{\left(j n_{j}\right)}\right)^{T}$ can be got via characteristic root, and then $W_{i j}$ can be expressed as

$$
W_{i j}=\left[\begin{array}{cccc}
\omega_{i 1}^{j 1} & \omega_{i 1}^{j 2} & \cdots & \omega_{i 1}^{j n_{j}} \\
\omega_{i 2}^{j 1} & \omega_{i 2}^{j 2} & \cdots & \omega_{i 2}^{j n_{j}} \\
\vdots & \vdots & \vdots & \vdots \\
\omega_{i n_{i}}^{j 1} & \omega_{i n_{i}}^{j 2} & \cdots & \omega_{i n_{i}}^{j n_{j}}
\end{array}\right],
$$

where the column vector of $W_{i j}$ is the column vector of influence degree that elements in $C_{i}$ have on those in $C_{j}$. If 

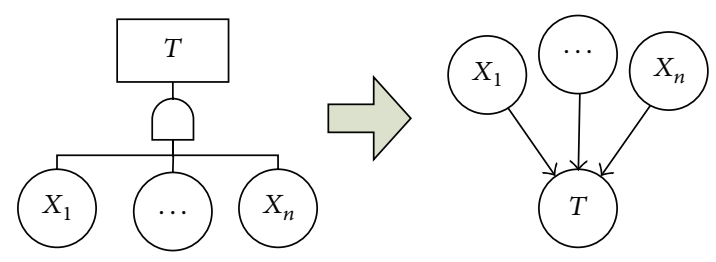

\begin{tabular}{lcccc}
\hline$X_{1}$ & $X_{2}$ & $\cdots$ & $X_{n}$ & $T$ \\
\hline 0 & 0 & $\cdots$ & 0 & 0 \\
1 & 0 & $\cdots$ & 0 & 0 \\
1 & 1 & $\cdots$ & 0 & 0 \\
$\vdots$ & $\vdots$ & $\vdots$ & $\vdots$ & $\vdots$ \\
1 & 1 & 1 & 1 & 1 \\
\hline
\end{tabular}

Figure 2: And-gate structures.
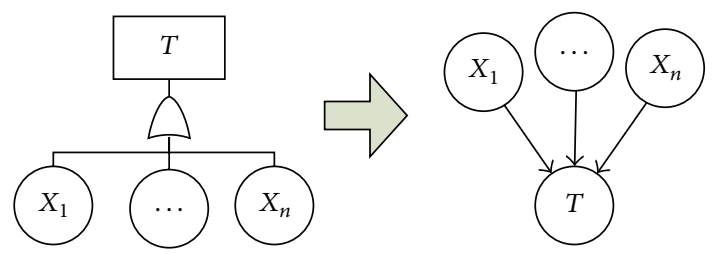

\begin{tabular}{ccccc}
\hline$X_{1}$ & $X_{2}$ & $\cdots$ & $X_{n}$ & $T$ \\
\hline 0 & 0 & $\cdots$ & 0 & 0 \\
1 & 0 & $\cdots$ & 0 & 1 \\
0 & 1 & $\cdots$ & 0 & 1 \\
$\vdots$ & $\vdots$ & $\vdots$ & $\vdots$ & $\vdots$ \\
1 & 1 & 1 & 1 & 1 \\
\hline
\end{tabular}

FIGURE 3: Or-gate structures. elements are in $C_{i}$, then $\omega_{i j}=0$, and the hypermatrix under the guidelines is

$$
W=\left[\begin{array}{cccc}
W_{11} & W_{12} & \cdots & W_{1 N} \\
W_{21} & W_{22} & \cdots & W_{2 N} \\
\vdots & \vdots & \vdots & \vdots \\
W_{N 1} & W_{N 2} & \cdots & W_{N N}
\end{array}\right] .
$$

(3) Building the Weighted Hypermatrix. W hypermatrix's subblock $W_{i j}$ is normalized, while $W$ is not. Every element of $B_{N}$ compares against the importance of guideline $C_{j}(j=$ $1,2, \ldots, N)$. The ordering weight of element sets which are irrelevant with $C_{j}$ is zero, and it can reach the weighted matrix:

$$
A=\left[\begin{array}{cccc}
a_{11} & a_{12} & \cdots & a_{1 N} \\
a_{21} & a_{22} & \cdots & a_{2 N} \\
\vdots & \vdots & \vdots & \vdots \\
a_{N 1} & a_{N 2} & \cdots & a_{N N}
\end{array}\right] .
$$

Then the weighted hypermatrix $\bar{W}=\left(\overline{W_{i j}}\right)$ and $\overline{W_{i j}}=$ $a_{i j} W_{i j}, i, j=1,2, \ldots, N$.

(4) Calculating the Limit Hypermatrix and Determining the Weight Value of Every Element. The value of hypermatrix $\bar{W}$ 's element $\overline{W_{i j}}$ reflects one step dominance that element $i$ has over $j$.

Let $\bar{W}$ multiply itself until the product reaches a convergence (each time it multiplies, it needs the column to be normalized once); then it gets the limit hypermatrix $\overline{W^{\infty}}=$ $\lim _{x \rightarrow \infty} \overline{W^{t}}$ whose column vector is the average limit relative ordering vector of elements.
3.4. Occurrence Probability of Top Events. Top events are undesired events (accident or fault). Its occurrence probability is calculated by referring to the fault tree and the occurrence probability of basic events. In the Fault Tree Analysis, it first needs to solve all minimal cut sets (minimal path sets) before calculating the occurrence probability of top events and intermediate events, then using the inclusion-exclusion theorem for precise calculations, or perform approximate calculation through exclusive approximate or independent approximate. In Bayesian network, there is no need to solve cut sets. Joint probability distribution can be used to directly calculate the occurrence probability of top events $(T)[20]$ :

$$
\begin{aligned}
P & (T=1) \\
& =\sum_{E_{1}, \ldots, E_{M-1}} P\left(E_{1}=e_{1}, \ldots, E_{M-1}=e_{M-1}, T=1\right),
\end{aligned}
$$

where node $E_{i}(1 \leq i \leq M-1)$ corresponds to the intermediate events and bottom events in the fault tree, $e_{i} \in$ $\{0,1\}$ represents whether event $E_{i}$ will occur, and $M$ is the number of nodes in Bayesian network.

3.5. Quantitative Analysis of Importance Degree. Quantitative assessment of oil wharf handling risks is based on analysis of the importance degree, which is to analyze the effect degree of every basic event to the occurrence probability of top events. It is an essential mean to provide information for us to modify the system. In Bayesian network, it is easy to calculate the importance degree of bottom events $E_{i}$ through its reasoning algorithm (e.g., Clique Tree Propagation Algorithm and Bucket Exclusion Algorithm).

(1) The analysis of structural importance is to analyze the importance degree of every basic event from the perspective of network structure. Namely, to analyze the extent which the basic events will impose on the occurrence probability of top events, without considering the occurrence probability of 
the basic events, or, in other words, supposing the occurrence probability of all basic events is equal.

Importance degree of structure is as follows:

$$
\begin{aligned}
I_{i}^{\text {st }} & =P\left(T=1 \mid E_{i}=1, P\left(E_{j}=1\right)=0.5,1 \leq j \neq i\right. \\
& \leq N)-P\left(T=1 \mid E_{i}=0, P\left(E_{j}=1\right)=0.5,1 \leq j\right. \\
& \neq i \leq N) .
\end{aligned}
$$

(2) The analysis of probability importance is to analyze the importance degree of every basic event from the perspective of probability, reflecting the effect degree of the change of occurrence probability of basic events to that of top events.

Importance Degree of Probability is as follows:

$$
I_{i}^{\mathrm{Pr}}=P\left(T=1 \mid E_{i}=1\right)-P\left(T=1 \mid E_{i}=0\right) .
$$

(3) The critical importance degree measures the importance degree of all basic events from the perspective of sensitivity and the occurrence probability of its own.

Critical Importance Degree is as follows:

$$
\begin{aligned}
& I_{i}^{\mathrm{Cr}} \\
& \quad=\frac{P\left(E_{i}=1\right)\left(P\left(T=1 / E_{i}=1\right)-P\left(T=1 / E_{i}=0\right)\right)}{P(T=1)} .
\end{aligned}
$$

3.6. Algorithm. A binary simply connected Bayesian network is plotted through mapping fault tree. To calibrate the basic events by ANP decision-making method, it will be easy to calculate the importance degree of basic events and the probability of top events. The calculation rules are as follows.

Rule 1. If event is $X_{i}$ and connection event is $P_{i j}$, then $X_{i} \stackrel{P_{i j}}{\longrightarrow}$ $X_{j}$, and $p\left(X_{j}=1\right)=x_{i} p_{i j}, p_{i j}=0$ or 1 .

Rule 2. If event is $X_{i-m}, X_{i-m+1}$, and $\ldots$ and $X_{i+n}$ and connection event is $P_{i j}$,

$$
\begin{aligned}
& \text { And-gate: } \bigcap_{k=i-m}^{k=i+n} X_{k} \stackrel{P_{i j}}{\longrightarrow} X_{j} \text {, and } \\
& p\left(X_{j}=1\right)=\sum_{k=i-m}^{k=i+n} p\left(X_{k}\right) \times p_{i j} \\
& =x_{i-m} \times x_{i-m+1} \times \cdots \times x_{i} \times \cdots \times x_{i+n} \times 1 . \\
& \text { Or-gate: } \bigcup_{k=i-m}^{k=i+n} X_{k} \stackrel{P_{i j}}{\longrightarrow} X_{j} \text {, and } \\
& p\left(X_{j}=1\right)=\sum_{k=i-m}^{k=i+n} p\left(X_{k}\right) \times p_{i j} \\
& =1-\left(1-x_{i-m}\right) \times\left(1-x_{i-m+1}\right) \times \cdots \\
& \times\left(1-x_{i}\right) \cdot \times \cdots \times\left(1-x_{i+n}\right) \times 1 \text {. }
\end{aligned}
$$

Combined with the rules, steps for quantitative calculations are as follows.
Step 1. Map the fault tree onto a Bayesian Network model and calibrating the occurrence probability of basic event $X_{i}$ as $x_{i}$, and then analyze the structural importance. $x_{i}$ can be calibrated as any value in set $(0,1)$ (it has no effect on the structural importance).

Step 2. Let the occurrence probability of basic event $X_{i}$ be $p\left(X_{i}=1\right)=x_{i}$; the probability of other events is tentatively set as 0 .

Step 3. Taking the occurrence probability calibrated in Step 2 as input to update the probability of subnode $X_{j}$ according to ANP calibration algorithm, $0 \rightarrow p\left(X_{j}=1\right)$.

Step 4. $j \rightarrow i$, subnode $X_{j} \rightarrow X_{i}$, return to Step 2, and continue to calculate the probability of the next layer. Circulate the step until the occurrence probability of top events is worked out. Let the occurrence probability of this top event $p(T=1)$ be an intermediate output.

Step 5. According to formulas (6) to (8) and combining with the occurrence probability of the top event in Step 4, the structural importance, probability importance, and critical importance of all basic events are calculated backwards. These three indicators are the final output and the algorithm ends.

\section{Case Study}

A fire happens only when combustible, oxidant, and ignition sources are all available at the same time. Lack of any one of them will make a fire impossible; thus they make three necessary elements of fire. As for oil wharf handling, as long as there is ignition source, a fire or explosion might happen once oil leaks.

4.1. Build Fault Tree. This paper chooses gasoline as the object of analysis as it is common goods in wharf handling. Gasoline is a flammable liquid with a low flash point in Section 3.1 category. Its fire risk level is class B [21] with characteristics of inflammable, explosive, evaporable, and it is easy to produce and build up static electricity. And also it is easy to accumulate. If gasoline leaks while oil wharf handling, the leaked gasoline will gradually accumulate to be a liquid pool of certain thickness and dimension. Once ignited by an ignition source, the pool will trigger a pool fire. And if gasoline vapor constantly spreads in the air and the concentration reaches to the explosion limit, an explosion accident will suddenly happen once the ignition source appears.

This paper takes gasoline fire accident and explosion in oil wharf handling as the top event to analyze its risks by building a fault tree model. After a research in port of Dalian, Beibu Gulf, and some other ports in China, one top event, thirteen intermediate events, and thirty-two basic events are chosen as trigger events and impact factors constitute the fault tree. Figure 4 is for the fault tree model, and the letter code and name of all basic events are listed in Table 1 .

4.2. Mapping the Fault Tree into a Bayesian Network. According to the mapping method described in Section 3.2, this step 
TABLE 1: Events list of gasoline fire accident and explosion in oil wharf handling.

\begin{tabular}{|c|c|c|}
\hline Events type & Letter code & Events name \\
\hline Top event & $T$ & Fire accident and explosion in oil wharf handling \\
\hline \multirow{15}{*}{ Intermediate events } & $A_{1}$ & Sources of ignition \\
\hline & $A_{2}$ & Leakage \\
\hline & $B_{1}$ & Open fire \\
\hline & $B_{2}$ & Electrostatic sparks \\
\hline & $B_{3}$ & Electrical sparks \\
\hline & $B_{4}$ & Friction, shock sparks \\
\hline & $B_{5}$ & Automobile exhaust sparks \\
\hline & $B_{6}$ & Tank leak \\
\hline & $B_{7}$ & Marine loading arm \\
\hline & $B_{8}$ & Pipe leak \\
\hline & $C_{1}$ & Electrostatic sparks on human body \\
\hline & $C_{2}$ & Electrostatic sparks of oil products \\
\hline & $C_{3}$ & Fracture on outside and inside of the arm \\
\hline & $D_{1}$ & Body static \\
\hline & $D_{2}$ & Static electricity accumulation of oil products \\
\hline \multirow{32}{*}{ Basic events } & $X_{1}$ & Unlawful hot work \\
\hline & $X_{2}$ & Open fire on near vessels \\
\hline & $X_{3}$ & Fire brought by smoking or unlawful behavior \\
\hline & $X_{4}$ & Do not touch the electrostatic eliminating device before entering the field \\
\hline & $X_{5}$ & Touch conductors of different voltage \\
\hline & $X_{6}$ & Electrostatic sparks on chemical fiber clothes \\
\hline & $X_{7}$ & Flow too fast \\
\hline & $X_{8}$ & Poorly grounded \\
\hline & $X_{9}$ & Oil products are mixed with water and other impurities \\
\hline & $X_{10}$ & Design defects in process and devices \\
\hline & $X_{11}$ & Improper electric options (such as the selection of nonexplosion-proof electrics) \\
\hline & $X_{12}$ & Electrical failure \\
\hline & $X_{13}$ & Operation against rules \\
\hline & $X_{14}$ & Short circuit or overload \\
\hline & $X_{15}$ & Insulating flange of marine loading arm malfunction (stray current sparks of vessel body) \\
\hline & $X_{16}$ & Personnel wear spikes \\
\hline & $X_{17}$ & Metal hosepipe, iron tools friction, or collision with ground \\
\hline & $X_{18}$ & The bearings of device has not been timely maintained \\
\hline & $X_{19}$ & Vehicles or equipment collide with each other \\
\hline & $X_{20}$ & Vehicles entering the field has not been equipped with back-fire relief valve \\
\hline & $X_{21}$ & Back-fire relief valve of vehicles malfunction \\
\hline & $X_{22}$ & Valve damaged \\
\hline & $X_{23}$ & Safety accessory abnormal \\
\hline & $X_{24}$ & Corrosion leak \\
\hline & $X_{25}$ & Fracture and leakage resulted from uneven settlement and adverse natural conditions \\
\hline & $X_{26}$ & Excessive tank filling \\
\hline & $X_{27}$ & The interface is not tight enough \\
\hline & $X_{28}$ & Poor natural conditions of typhoon and others \\
\hline & $X_{29}$ & Strike of mooring rope \\
\hline & $X_{30}$ & Pressure, temperature too high \\
\hline & $X_{31}$ & During loading and unloading operations, ship displacement over limit \\
\hline & $X_{32}$ & External shocks from vehicles, machines, and so forth \\
\hline
\end{tabular}




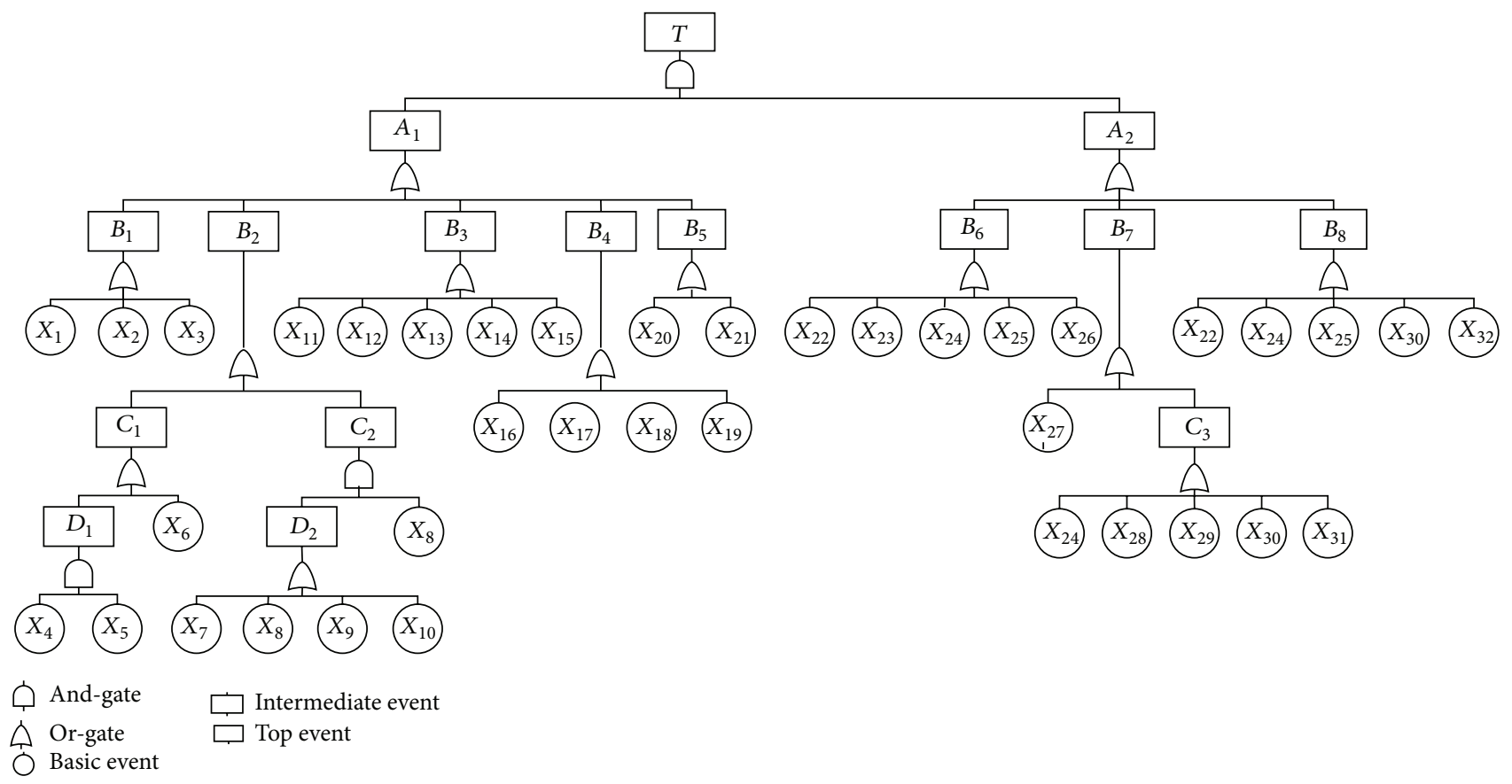

FIGURE 4: Fault tree model of gasoline fire accident and explosion in oil wharf handling.

is to map the fault tree of gasoline fire accident and explosion during oil wharf handling in Figure 4 into corresponding Bayesian network as Figure 5 shows. The conditional probability table among nodes will be given according to the Andgate and Or-gate in Figures 3 and 4 as described.

In accordance with the logic relation shown in Figure 5, the joint probability distribution function in the Bayesian network of gasoline fire and explosion in oil wharf handling is

$$
\begin{aligned}
p( & \left.t, a_{1}, a_{2}, b_{1}, b_{2}, \ldots, b_{8}, c_{1}, c_{2}, c_{3}, d_{1}, d_{2}, x_{1}, x_{2}, \ldots, x_{32}\right) \\
= & p\left(x_{1}\right) p\left(x_{2}\right), \ldots, p\left(x_{32}\right) p\left(\frac{d_{1}}{x_{4}}, x_{5}\right) \\
\cdot & p\left(\frac{d_{2}}{x_{7}}, x_{8}, x_{9}, x_{10}\right) p\left(\frac{c_{1}}{d_{1}}, x_{6}\right) p\left(\frac{c_{2}}{d_{2}}, x_{8}\right) \\
\cdot & p\left(\frac{c_{3}}{x_{24}}, x_{28}, x_{29}, x_{30}, x_{31}\right) p\left(\frac{b_{1}}{x_{1}}, x_{2}, x_{3}\right) \\
\cdot & p\left(\frac{b_{2}}{c_{1}}, c_{2}\right) p\left(\frac{b_{3}}{x_{11}}, x_{12}, x_{13}, x_{14}, x_{15}\right) \\
& \cdot p\left(\frac{b_{4}}{x_{16}}, x_{17}, x_{18}, x_{19}\right) p\left(\frac{b_{5}}{x_{20}}, x_{21}\right) \\
& \cdot p\left(\frac{b_{6}}{x_{22}}, x_{23}, x_{24}, x_{25}, x_{26}\right) p\left(\frac{b_{7}}{c_{3}}, x_{27}\right) \\
& \cdot p\left(\frac{b_{8}}{x_{22}}, x_{24}, x_{25}, x_{30}, x_{32}\right) p\left(\frac{a_{1}}{b_{1}}, b_{2}, b_{3}, b_{4}, b_{5}\right) \\
& \cdot p\left(\frac{a_{2}}{b_{6}}, b_{7}, b_{8}\right) p\left(\frac{t}{a_{1}}, a_{2}\right) .
\end{aligned}
$$

4.3. The ANP Calibration of Basic Event in Bayesian Network. The essential data (basic calibration of absolute value [22]) of 32 basic events has to be collected in accordance with the Delphi method. Then to figure out the weight value of basic events, according to the ANP method mentioned, and make it the occurrence probability value of basic events. See Table 2 for part of the probability value.

4.4. Calculating the Importance Degree. Figure out the structural importance according to formula (6) in Section 3.5. Partial probability values are shown in Table 3.

The order for structural importance of basic events is

$$
\begin{aligned}
I(27) & =I(32)>I(26)>I(20)=I(11)=I(16) \\
& >I(1)=I(2)>I(22)=I(24)=I(31) \\
& >I(3)>I(30)=I(29)>I(4)=I(5) \\
& >I(18)=I(19)=I(21)=I(6)=I(12) \\
& =I(13)=I(14)=I(15)=I(17)>I(10) \\
& =I(8) .
\end{aligned}
$$

The value of basic events has no effect on the order of structural importance in terms of the definition of the structural importance. If we only consider the position of basic events in the fault tree structure, $X_{27}$ and $X_{32}$ are of the highest importance followed by $X_{26}$, while $X_{8}$ is of the least importance. When managements after fire accidents and explosion in oil wharf handling are considered to improve the safety of the system, projects targeting at $X_{27}$ and $X_{32}$ can be arranged first. Another choice is to work out a checklist for fire and explosion in oil wharf handling in accordance with the above 


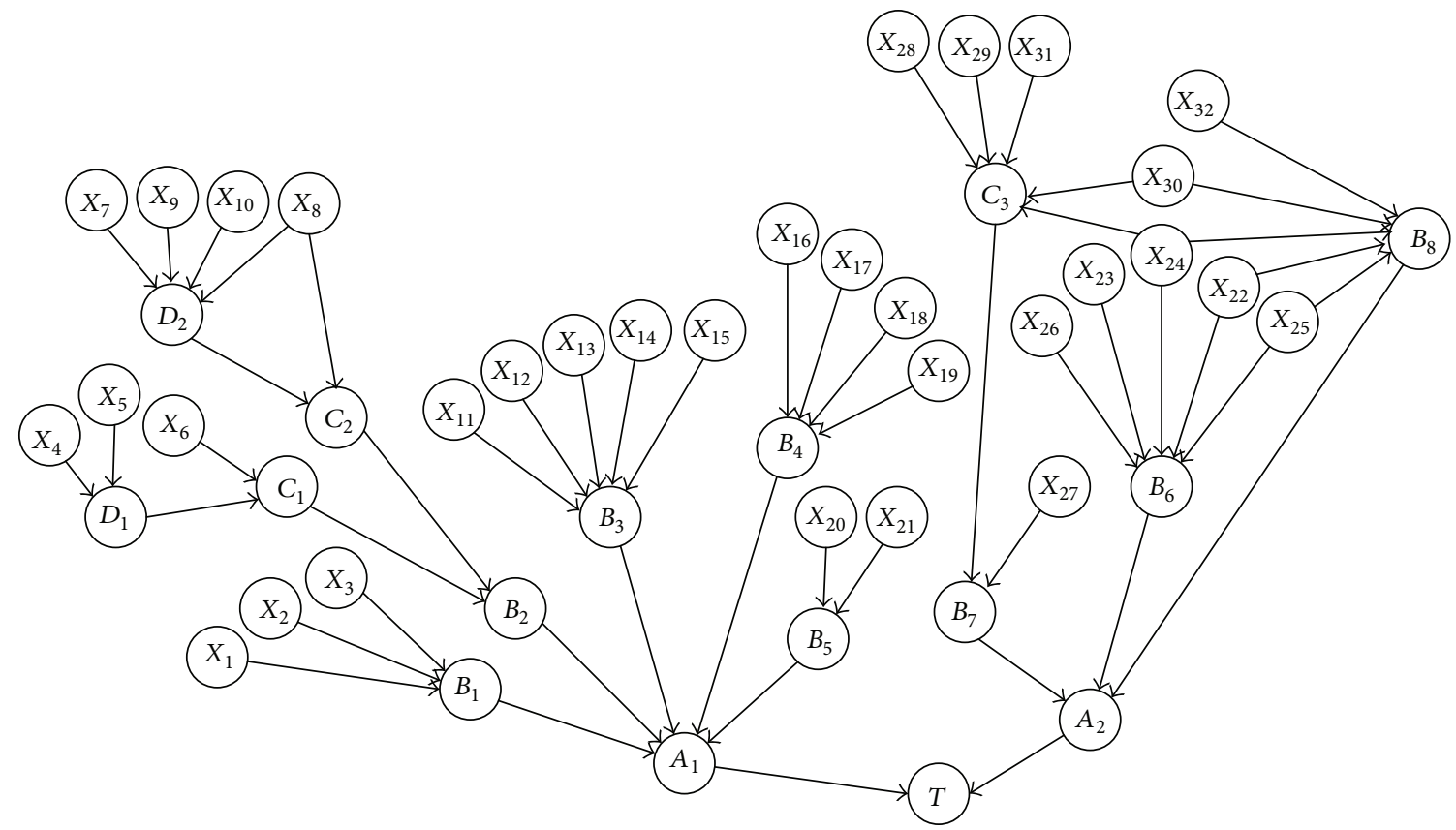

FIGURE 5: Bayesian network of gasoline fire and explosion in oil wharf handling.

TABLE 2: The occurrence probability value of basic events.

\begin{tabular}{lc}
\hline Basic events & Calibration probability value \\
\hline$X_{1}$ & 0.00251 \\
$X_{2}$ & 0.0076 \\
$X_{3}$ & 0.0076 \\
$\vdots$ & $\vdots$ \\
$X_{15}$ & 0.0142 \\
$X_{16}$ & 0.02614 \\
$\vdots$ & $\vdots$ \\
$X_{32}$ & 0.04807 \\
\hline
\end{tabular}

TABLE 3: The structural importance.

\begin{tabular}{lc}
\hline Basic events & The structural importance \\
\hline$X_{1}$ & 0.043209876543 \\
$X_{2}$ & 0.043209876543 \\
$X_{3}$ & 0.037037037037 \\
$\vdots$ & $\vdots$ \\
$X_{15}$ & 0.018518518519 \\
$X_{16}$ & 0.049382716049 \\
$\vdots$ & $\vdots$ \\
$X_{32}$ & 0.100823045267 \\
\hline
\end{tabular}

structural importance order, in order to check the important items first and to treat them more careful.

The probability importance and the critical importance can be figured out in a similar way. In Tables 4 and 5, there are parts of the results.
TABle 4: Probability importance.

\begin{tabular}{lc}
\hline Basic events & Probability importance \\
\hline$X_{1}$ & 0.338029738618 \\
$X_{2}$ & 0.338029738618 \\
$X_{3}$ & 0.324165292257 \\
$\vdots$ & $\vdots$ \\
$X_{15}$ & 0.155671058198 \\
$X_{16}$ & 0.377330394618 \\
$\vdots$ & $\vdots$ \\
$X_{32}$ & 0.331552854357 \\
\hline
\end{tabular}

The order for probability importance of basic events is

$$
\begin{aligned}
\operatorname{Ig}(11) & >\operatorname{Ig}(16)=\operatorname{Ig}(20)>\operatorname{Ig}(2)=\operatorname{Ig}(1)>\operatorname{Ig}(27) \\
& =\operatorname{Ig}(32)>\operatorname{Ig}(3)>\operatorname{Ig}(26)>\operatorname{Ig}(17) \\
& =\operatorname{Ig}(18)=\operatorname{Ig}(19)=\operatorname{Ig}(13)=\operatorname{Ig}(21) \\
& =\operatorname{Ig}(14)=\operatorname{Ig}(15)=\operatorname{Ig}(12)>\operatorname{Ig}(6) \\
& >\operatorname{Ig}(24)=\operatorname{Ig}(31)=\operatorname{Ig}(22)>\operatorname{Ig}(29) \\
& =\operatorname{Ig}(30)>\operatorname{Ig}(10)>\operatorname{Ig}(8)>\operatorname{Ig}(5)=\operatorname{Ig}(4) \\
& >\operatorname{Ig}(28)=\operatorname{Ig}(9)=\operatorname{Ig}(25)=\operatorname{Ig}(7) \\
& =\operatorname{Ig}(23) .
\end{aligned}
$$

According to the order above, it can be seen that reducing the occurrence probability of basic event $X_{16}$ could lower the occurrence probability of the top event in a more efficient way than reducing probability of any other basic events. What 
TABLE 5: Critical importance degree.

\begin{tabular}{lc}
\hline Basic events & Critical importance degree \\
\hline$X_{1}$ & 0.013441370697 \\
$X_{2}$ & 0.040698971035 \\
$X_{3}$ & 0.039029683879 \\
$\vdots$ & $\vdots$ \\
$X_{15}$ & 0.035019597445 \\
$X_{16}$ & 0.156258014109 \\
$\vdots$ & $\vdots$ \\
$X_{32}$ & 0.252488627038 \\
\hline
\end{tabular}

follows in order is $X_{16}, X_{20}, X_{2}, X_{1}, X_{27}$ and $X_{32}$, while $X_{23}$ is the least sensitive one.

The order for probability importance of basic events is

$$
\begin{aligned}
C g(27) & >C g(17)>C g(32)>C g(26)>C g(16) \\
& >C g(22)>C g(13)>C g(19)>C g(14) \\
& >C g(12)>C g(24)>C g(2)>C g(3) \\
& >C g(20)>C g(15)>C g(21)>C g(11) \\
& >C g(6)>C g(18)>C g(30)>C g(1) \\
& >C g(31)>C g(10)>C g(8)>C g(29) \\
& >C g(5)=C g(4)>C g(28)=C g(9) \\
& =C g(25)=C g(7)=C g(23) .
\end{aligned}
$$

Compared with probability importance, the importance degree of $X_{11}$ has dropped because of its low occurrence probability, while basic event $X_{27}$ rises. It is not only because $X_{27}$ 's high sensitivity, but also for the high probability of it.

4.5. Summary. Importance degree calculation through Bayesian network can reflect the actual status of things in a more comprehensive way. For example, the value of probability $X_{8}$ (poorly grounded) is bigger than $X_{32}$ (external shock from vehicles, machines, etc.), but $I(32)>I(8)$, $\operatorname{Ig}(32)>\operatorname{Ig}(8)$, and $\operatorname{Cg}(32)>C g(8)$, which reflects that the value of $X_{32}$ is bigger regardless of the network structure, probability changes, sensitivity, or the occurrence probability of its own. In real situation of oil wharf handling, there will be machinery operations such as maintenance vehicles and lifting operation. In the past, there were numerous cases where the vehicles and machines crash on pipelines and stands. As a result, the Ministry of Transport released the Port Safety Facilities Directory in 2014 and pointed that some anticollision equipment in some areas of the wharf should be set up. Ground connection in oil wharf apparatuses and constructions will exert a tremendous influence on safety, and the current law requires an inspection of lighting protection grounding every half a year, so the influence that $X_{8}$ has on the network has reduced. From all above, we can see that the Bayesian network has broken the limit that the extent of effect can only be expressed in probability value, which shows its objectiveness and reasonableness.

\section{Conclusion}

It is rarely seen to assess the risk of oil wharf handling through Bayesian network method. Taking advantage of Bayesian network, this paper maps the fault tree model onto Bayesian network. The problem of quantitative risk assessment of oil wharf handling has been solved effectively both by Bayesian network and ANP decision-making methods, which expands the range of Bayesian network's and ANP's application greatly. Main conclusions and prospects are as follows:

(1) Replacing the hierarchical relationships with network structural relationships via Saaty's ANP decisionmaking methods is the way to calibrate the fuzzy value of relative probability of basic events, which will be the probability value of basic events. This has solved the problem that there are interdependent relationships and feedback among basic events, which is impossible for traditional methods to deal with. This method makes the calculation results more accurate and credible. In the meantime, it makes up for the lack of database of oil wharf handling accidents in China.

(2) Building the Bayesian network of oil wharf handling risk assessment model will not only make the tree causality more clear in logic, but also make the expression of conditional probability relations in different layers accurate. Taking advantage of the reasoning algorithm with Bayesian network, it is easy to figure out the importance degree of basic events so as to acquire the importance extent that basic events mean to the occurrence of accidents from various aspects.

(3) In the safety assessment of oil wharf handling, a combination of ANP decision-making methods and Bayesian network will give the analysis result more realistic significance and pertinence in finding the weak link in the process of oil wharf handling so as to improve the working condition.

(4) Oil wharf handling is a dynamic process. The Bayesian network built in this paper is based on a static logic and static accident mechanism. How to build a dynamic Bayesian network in order to make the analysis of the risk more accurate in oil wharf handling will be the key problem of researches in this area in the future.

\section{Competing Interests}

The authors declare that they have no competing interests.

\section{References}

[1] G.-Q. Sun and M.-Y. Liu, Safety Management and Technology of Hazardous goods at Harbor, China Communication Express, Beijing, China, 2013.

[2] H. Zhi-Qiang, L. Min-Yan, P. Si-Yi, and X. Hong-Wei, "Key technology of risk assessment of major hazard in port \& 
waterway engineering," China Safety Science Journal, vol. 19, no. 5, pp. 135-139, 2009.

[3] Y. F. Wang, Y. L. Li, B. Zhang, P. N. Yan, and L. Zhang, "Quantitative risk analysis of offshore fire and explosion based on the analysis of human and organizational factors," Mathematical Problems in Engineering, vol. 2015, Article ID 537362, 10 pages, 2015.

[4] G.-P. Cong, J.-J. Gao, J.-F. Yang, and W.-B. Liu, "Risk assessment based on fault tree analysis for damaged pipe repair during operation in petrochemical plant," Transactions of Tianjin University, vol. 19, no. 1, pp. 70-78, 2013.

[5] S.-P. Zhao, Z.-C. Chen, A.-G. Xuan, and T.-Z. Huang, "Application of FTA based on SDG-HAZOP for production of polypropylene," Journal of Safety Science and Technology, vol. 9, no. 8, pp. 152-155, 2013.

[6] L. J. Zhao, X. L. Wang, and Y. Qian, "Analysis of factors that influence hazardous material transportation accidents based on Bayesian networks: a case study in China," Safety Science, vol. 50, no. 4, pp. 1049-1055, 2012.

[7] W.-G. Li, Q. Yu, and R.-C. Luo, "Application of fuzzy analytic hierarchy process and neural network in power transformer risk assessment," Journal of Central South University of Technology, vol. 19, no. 4, pp. 982-987, 2012.

[8] L. Yang, R. Zhang, T. Hou, Z. Hao, and J. Liu, "Hesitant cloud model and its application in the risk assessment of 'the twentyfirst century maritime silk road"' Mathematical Problems in Engineering, vol. 2016, Article ID 5620803, 11 pages, 2016.

[9] General Administration of Quality Supervision,Inspection and Quarantine of the People's Republic of China(AQSIQ), Standardization Administration of China. GB6944-2012, Classification and Code of Dangerous Goods, Standards Press of China, Beijing, China, 2012.

[10] General Administration of Quality Supervision, Inspection, and Quarantine of the People's Republic of China (AQSIQ), "Major hazard identification of dangerous chemical," Standardization Administration of China GB18218-2009, Standards Press of China, Beijing, China, 2009.

[11] General Administration of Quality Supervision, Inspection, and Quarantine of the People's Republic of China (AQSIQ), "Classification and code for the hazardous and harmful factors in production process," Standardization Administration of China GB13861-2009, Standards Press of China, Beijing, China, 2009.

[12] P. Li, J.-C. Fan, and S.-J. Liu, "Quantitative analysis of borehole collapse in drilling base on fault tree analysis and bayesian networks," Journal of Safety Science and Technology, vol. 1, no. 10, pp. 143-149, 2014.

[13] O. P. Yadav, N. Singh, and P. S. Goel, "Reliability demonstration test planning: a three dimensional consideration," Reliability Engineering and System Safety, vol. 91, no. 8, pp. 882-893, 2006.

[14] J. Wallenius, J. S. Dyer, R. C. Fishbum, R. Steuer, and S. Zionts, "Multiple criteria decision making, multiattribute utility theory: recent accomplishments and what lies ahead," Management Science, vol. 54, no. 7, pp. 1336-1349, 2008.

[15] D.-Y. Chang, "Applications of the extent analysis method on fuzzy AHP," European Journal of Operational Research, vol. 95, no. 3, pp. 649-655, 1996.

[16] T. L. Saaty, "There is no mathematical validity for using fuzzy number crunching in the analytic hierarchy process," Journal of Systems Science and Systems Engineering, vol. 15, no. 4, pp. 457464, 2006.
[17] T. L. Saaty and L. T. Tran, "On the invalidity of fuzzifying numerical judgments in the analytic hierarchy process," Mathematical and Computer Modelling, vol. 46, no. 7-8, pp. 962-975, 2007.

[18] T. L. Saaty and L. T. Tran, "Fuzzy judgments and fuzzy sets," International Journal of Strategic Decision Sciences, vol. 1, no. 1, pp. 23-40, 2010.

[19] A. Hui and Z. Chuan-Jun, "Projet bidding risk assessment based on ANP-fuzzy," Construction Economy, vol. 11, no. 373, pp. 5760, 2013.

[20] Z.-B. Zhou, D.-D. Dong, and J.-L. Zhou, "Application of Bayesian networks in reliability analysis," System Engineering Theory and Practice, vol. 26, no. 6, pp. 95-100, 2006.

[21] Industry standard of the People's Republic of China, JTJ23799, Code for Fire Prevention Design of Oil Loading/Unloading Wharf, Ministry of Communications of PRC, Beijing, China, 1999.

[22] T. L. Saaty, Theory and Application of the Analytic Network Process, Beijing Institute of Technology Press, Beijing, China, 2015, Translated by J. Yanbing and L. Jianchang. 


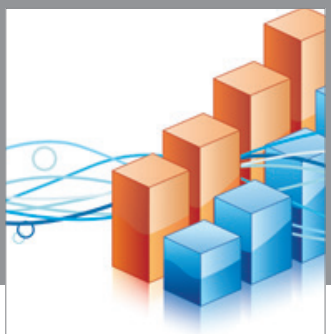

Advances in

Operations Research

vatem alat4

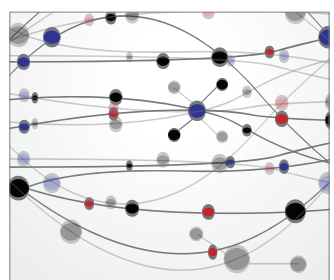

\section{The Scientific} World Journal
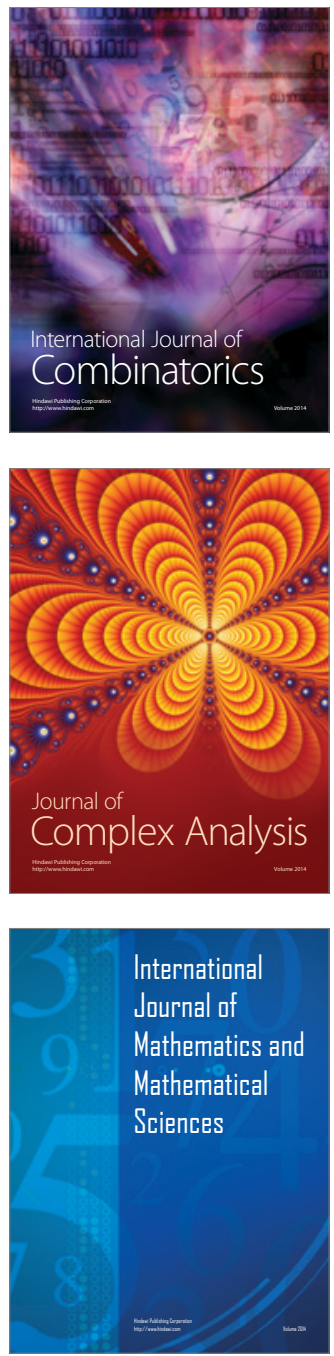
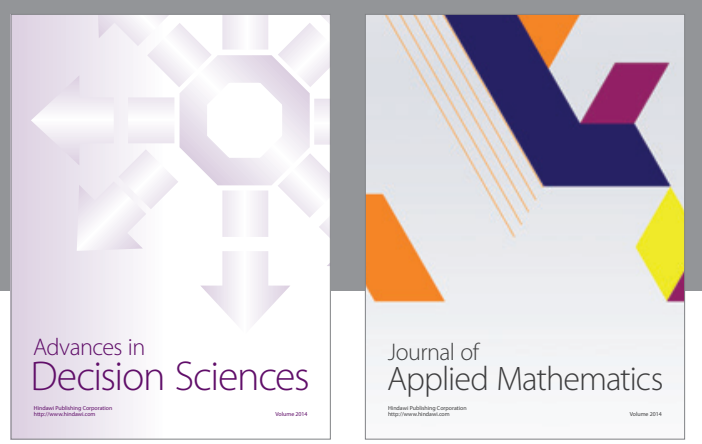

Algebra

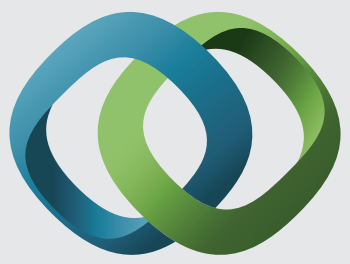

\section{Hindawi}

Submit your manuscripts at

http://www.hindawi.com
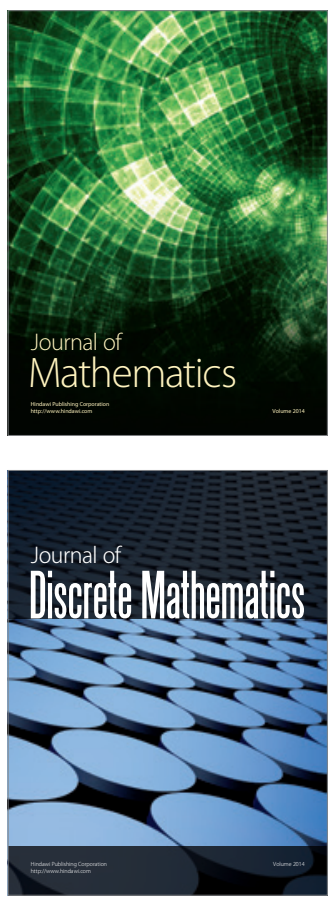

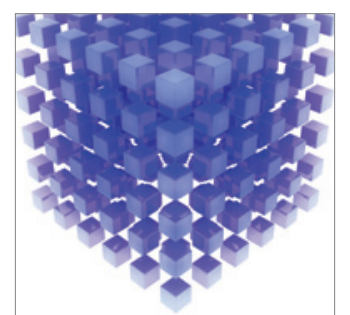

Mathematical Problems in Engineering
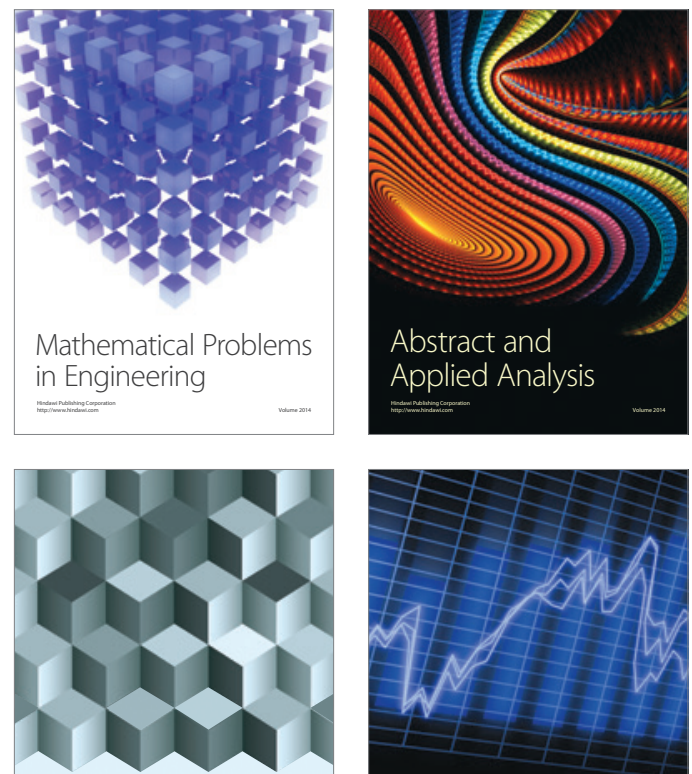

Journal of

Function Spaces

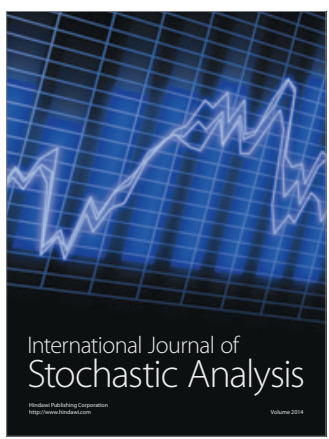

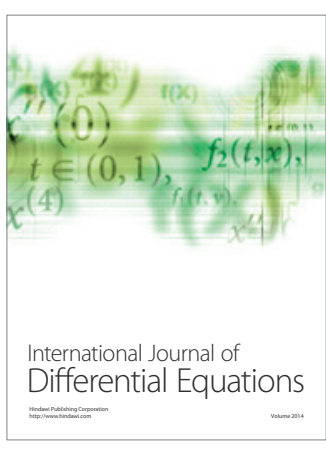
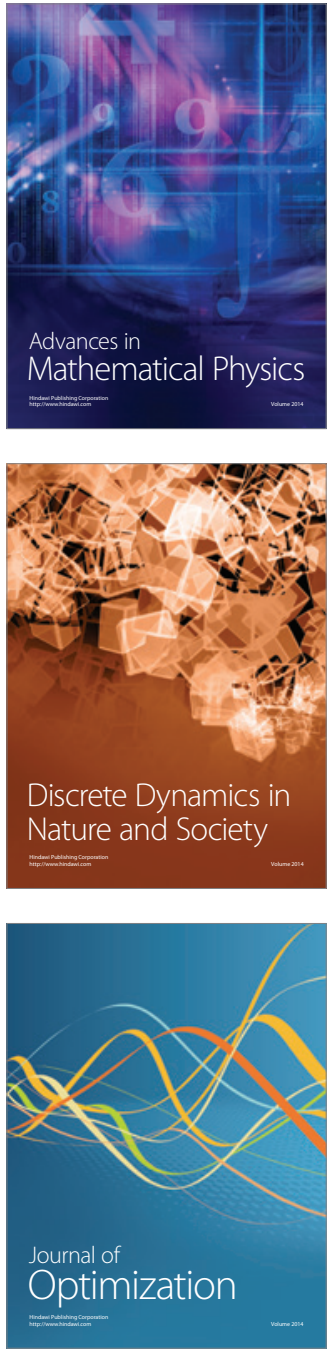